\title{
Ethics and Corporate Responsibility in International Relations
}

\author{
Clara Caselli
}

\begin{abstract}
The ethics of international relations must not be limited to airing principles on the nature of international trade. It must engage all the multifarious manifestations of the globalization process, therein identifying innovative means to handle relations in addition to devising an overall development strategy for Third World countries (including all the aspects related to reforms, production innovations, technology transfer and the re-conversion of sectors).

Fair relations on a worldwide basis will generate connections between different value production systems, and draw them into a global network where material and intangible/cultural elements merge in order to produce a flow of international relations. The content of these relations will not be merely economic but will favor people and cultures meeting.
\end{abstract}

Keywords: Ethics; Corporate Social Responsibility; Global Governance; Business Networks; International Institutions; Fair Trade; Globalisation

\section{Searching for 'Good Economics'}

For a number of years, the classic currents of economic and sociological thinking have been infused with the need for ethics, and have drawn greatly from anthropology, philosophy and so on (Sapelli 1995). This is not the appropriate place in which to examine such issues, however, for the purpose of this paper, it is important to highlight several significant aspects.

Firstly, the important issue concerning 'the purposes of economic actions, their influence on social development and, consequently, on man's happiness' (Sapelli 1995) must be highlighted. Ethics provides an alternative approach to the deterministic and mechanistic vision that historically views economics as a powerful anonymous mechanism where market forces - the 'invisible hand' of economics - transform the sum total of individual ambition into general happiness (Caselli 2002).

Secondly, there is an ever-increasing need for ethics set against the complex and dynamic background of contemporary global economics. This is not merely

\footnotetext{
*Full Professor of Management, University of Genoa (caselli@economia.unige.it)
} 
imposed from the outside in relation to economic actions with overtones of morality and duty, but from within. This is a fundamental prerequisite for rational conduct focusing on the long-term duration of any economic initiative.

Therefore, it is interesting to propose a number of straightforward considerations as a starting point, considerations which are intended as value judgments (Scola 2000):

a) there is no inbuilt ipso-facto contradiction between business and ethics;

b) it is difficult to do 'good business' on a long-term basis without considering the 'wellbeing' (in the sense of happiness) of those who implement actions and those with whom they come into contact;

c) economic performance forfeits its relationship with the very needs it intends to meet by excluding people. It turns into an ideological action in which the basic assumptions have very little in common with economic action (which is the search for creative balance in the trade-off between needs and resources);

d) if it becomes necessary to re-introduce the awareness of subjectivity and of the aims of economic actions, it is self-evident that, to a great extent, 'good' economics stems from anthropology rather than from ethics, that is to say from a vision of man which translates into economic culture;

e) economics that does not signify man as mere nothing, focuses on the dual awareness that needs and relations (behaviours), which are created to satisfy them, are 'human';

f) hence, even the market is not a 'state of nature' but a social construct (Persone \& Imprese 1995);

g) from this standpoint, the foundations of good economics are built on three main assumptions (Scola 2000). These might be illustrated by three rather simplified slogans: ultimately, nothing belongs to you (as proven by the biological phenomenon of death); therefore, do not thieve and, finally, use what you have to maximize happiness;

h) one can appreciate that an economic action is 'worthwhile' if it complies with the above principles: in this sense, ethics is the source of worth even in an economic context.

\section{At the Roots of Justice in the Trend to Internationalisation}

Historically speaking, internationalisation has been linked to commerce, but the advent of trade predates international trade, as we know it today. To this end, it is interesting to note how, right from the very beginning, the spread of rules and customs often took on a near sacred character in order to prevent commerce from deteriorating into mere robbery (Beretta, Maggioni, Senn, 1998).

Economic theories on international commerce deal with the issue of justice in different ways. For instance, the mercantilists believed that the function of trade was to accumulate wealth in gold, essential in order to exercise political and economic power. The classical theorists (beginning with Ricardo, later by Heckscher-Ohlin and including more recent contributions - Onida 1984) emphasized the positive effect of trade. They asserted that elements and resources are allocated differently, and developing them efficiently requires specialized 
production processes and, therefore, trade. In the post-war period, Marxist thought gave rise to a particularly animated debate, especially in Latin America. The essence of this was that trade is an 'unequal exchange' between rich and poor countries, the source of appropriation of surplus amounts which is generated by the exploitation of entire populations (Baran-Sweezy 1978; Palloix 1970; Amin 1974; Gunder Frank 1974).

The debate used to be carried out along fairly clear guidelines. However, given the complex articulated world in which we live today and with the advent of globalisation, the issues of justice and ethics within international relations can no longer be dealt with in such a straightforward manner. In particular, and to an increasingly large extent, international relations do not only involve the exchange of 'opposite' goods, that is to say raw materials in exchange for finished products.

Today, models of specialization have become highly developed. Trade in raw materials has gradually become less important while trade in intangible assets (over and above the intangible and service-related content of the trade in products) has become more so. Even developing countries have become active players in the world theatre (resulting from models based on the well-integrated development of trade and investment) and have begun to export finished products with an increasingly high technological content. Moreover, direct investment has gained a foothold alongside the trade in goods and most importantly, the so-called new forms of internationalisation have become widespread. Even internationalisation theories have had to measure up to the increasingly complex state of affairs. International occurrences can no longer be explained in terms of different levels of allocation or of rapacious imperialism: Dunning's eclectic vision, which has evolved to the extent of embracing the most recent new economic trends, typifies the need to come to terms with this complexity (Dunning 1982 and 2001).

A robustly ideological vision of global phenomena has certainly lost no ground. One only has to examine the highly critical attitude expressed by movements such as the no global pressure group on issues such as the expansion of multinational companies, the role of international institutions and the growth of international finance. Yet, at the same time, a new style of pragmatism is unfolding. There is a large body of evidence that draws on extensive well documented statistics and confirms that developing countries benefit from implementing policies focused on 'opening up' (World Bank 2001, Unctad 2002 and 2003).

Both positions have some limitations. The first lacks a sense of reality and, above all, the ability to devise feasible alternatives. There is a self-evident barrenness in proposals that entail easy debt (not viable in the long-term and discriminatory as poor countries would be excluded), price subsidies (with ensuing market mechanism distortion) and protectionism (which runs the risk of supporting uncompetitive entities). The second, with its ideology of total optimism, lacks the ability to see the down side of opening up - low wages, little respect for human rights, insufficient protection of employment and the environment, etc. More significantly, it fails to understand the conditions under which opening up international relations would actually be advantageous and a real source of development for countries. Moreover, open policy advocates are, paradoxically, often developing countries as demonstrated by the ongoing debate within the WTO (World Trade Organization). Indeed, those very countries used to be seen as the 
victims of open policies, whereas first world countries are searching for ways to protect their markets as shown, for instance, by the case of agricultural products.

Therefore, what do fairness and justice in international economic relations actually mean in a global world, given the increasing inter-dependency of markets?

\section{Development is the Name of Globalisation Ethics}

It is the very widespread nature, complexity and dynamics of current internationalisation trends that make it necessary to establish a concise concept that could take into account all the economic and non-economic aspects of globalisation. In this regard, the most suitable concept in order to measure ethics might be development, signified by growth in human and social capital, and as overall sustainability. How internationalisation/globalisation can be combined with development is the most interesting ethical issue.

The first step is to recognize that globalisation is not something mechanical but the result of human action translated into behaviours by interested parties (businesses, governments, institutions, consumers, etc.) and which originate from freedom (Caselli 1994). Trading, entering into economic as well as cultural relations, is a human need born from the quest for satisfaction (the satisfaction of a need), for recognition ('others' bear something which interests me, he exists 'for me') and for communication. There is certainly potential for conflict of interest between trading parties, but without some mutual trust there would be no trade (Beretta-Maggioni-Senn 1998). In this sense, trade is a relation entailing cooperation and rivalry, and it is always possible 'to do more' and achieve results that maximize mutual satisfaction. Accordingly, one realizes that ethics is not juxtaposed onto trade at a later stage; it is the element that makes it possible, that makes it a genuine exchange, in the sense of communication, the recognition of oth0ers and their dignity, reciprocal trust and honesty. We are dealing with 'sacred' virtues that by their very existence differentiate trade and internationalisation/globalisation from robbery.

The market, but more generally the various internationalisation environment elements, is the result of a human social construct with defined fundamental rules that govern economic actions and must be recognized by people. It is a cultural institution similar to the social anthropological concept. This form of social construct is especially evident with respect to the more complex aspects of globalization. For instance, choosing a joint venture as the basis of an undertaking implies diverse dynamic relations (with governments, potential partners, consumers and so on), which make every transaction unique.

The idea of justice as not being merely distributive has roots in this framework. Consequently, resources are seen as just one data element and the matter is played out in an attempt to gain an increasingly large 'slice of cake'. It is clear that the true challenge lies in the creation of wealth in the service of a vision that views people and their needs as its focal point. Therefore, the time of struggles against unfair trade has come to an end - the era of concerted action for development has started. 


\section{Global Governance and International Institutions}

The outlook for the above considerations is a world in which international relations are beset by deep crises and existing institutions demonstrate their inability to offer a minimum standard of global governance. Since the fall of the Berlin wall and the end of the Cold War when the world was divided into political blocs needs have become more fragmented and attitudes have become more multifaceted and complex. Moreover, there is no recognized world authority capable of projecting a specific world order with the necessary authority. Since Seattle, the horizontal and vertical contradictions that traverse international relations have been in the global limelight.

It is evident that in addition to the traditional contradictions between north and south, there are deep fractures between northern countries (USA versus Europe, for instance), between southern countries, between governments and so on. Faced with these difficulties, institutions like the World Trade Organization have provided defensive answers (a reduction in the range of business activity to be dealt with), to avoid problems and, above all, confrontation. They realize, however, that the main issue is re-building channels of communication and consensus amongst all the parties, particularly by opening the doors to debate within the civil society. In this sense, the problem concerns method. More recently international institutions have increasingly chosen this direction, organizing debating forums and round table sessions, but to all intents and purposes they run the risk of being ineffective.

It is impossible to create, in the words of the poet T. S. Eliot, 'systems so perfect that no one will need to be good' (Eliot 1963). In point of fact, it follows that ethics entails a discretionary and gratuitous aspect. Corporate social responsibility shows this up clearly in that, were it a question of legal compliance, it would no longer be social responsibility. In actual fact, ethics is a measure of economic action not an 'injection'. Faced with the perception of human needs, which to a great extent depend on an anthropological vision, one is able to devise a hierarchy and make choices which stand out on account of their inherent freedom.

\section{The Social and Economic Value Chain}

As explained previously, ethics at a global level is synonymous with development. It follows that the basic criterion for understanding the ethical level of relations is not one of defence, i.e. it is not merely concerned with defending rights, reporting crimes and claiming greater power when the wealth we have contributed to is shared out. It is instead concerned with nurturing the production of value (economic, social and human) where people live so as to produce authentic social leadership, in compliance with the so-called subsidiarity method (Vittadini 1998) and with ensuring that market mechanisms are endorsed. It is for this purpose that socio-competitive creative skills must be implemented (Molteni 2003).

The production of value is forging a series of connections (Caselli 2003), in the sense that it resembles the links in a chain that join the parties belonging to an economic system in a sequence without continuity solutions. They connect all levels from local to national, each of which is endowed with its own uniqueness as it coincides with the original contribution from each contributor's mission (Figure 
1). The ensuing synthesis is a national model for the production of economic and social value which reflects the culture, or the cultures. This model is once again, absolutely unique.

Figure 1: The Value Chain.

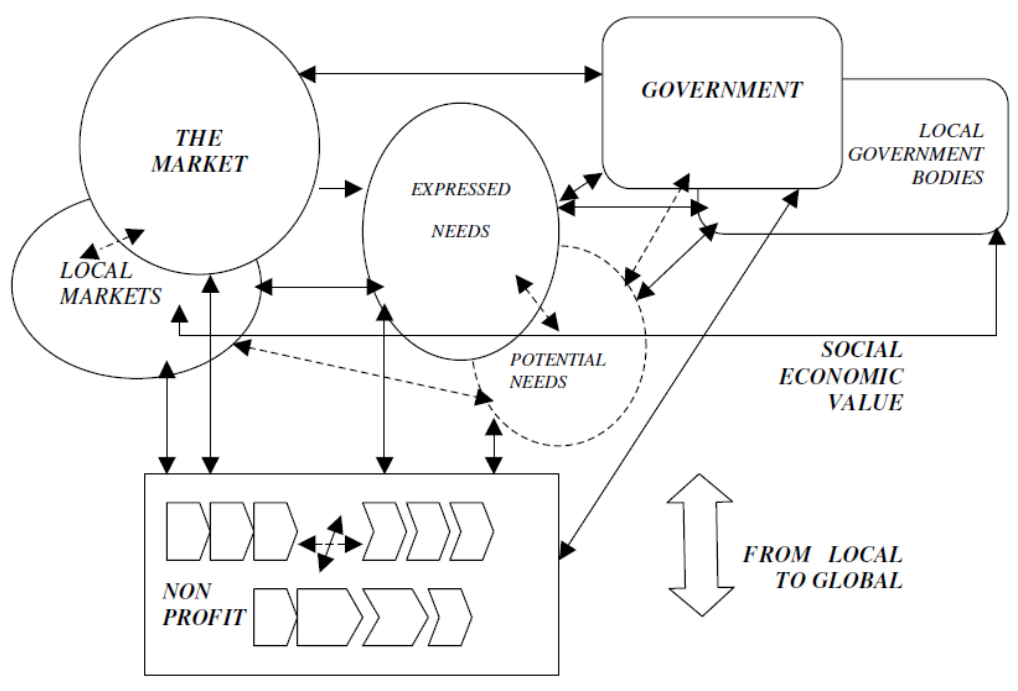

When a system opens up on a global level, a number of relationships come into being between value production systems. The greater the benefits of the opening process, the greater the extent of relationships amongst all the different players, involving not merely the political, institutional or macro players. The capacity to generate development is directly proportional to the strength and stability of the relations between each national value-production system, the range of players as well as the intensity and richness of the debate between different anthropological visions. In any case, the centre and the ethical test of the relationships that come into being (Figure 2) can be measured by the centrality accorded to human capital and to the fact that human development is seen as the ultimate goal of economic actions.

Figure 2: The International Value Chain

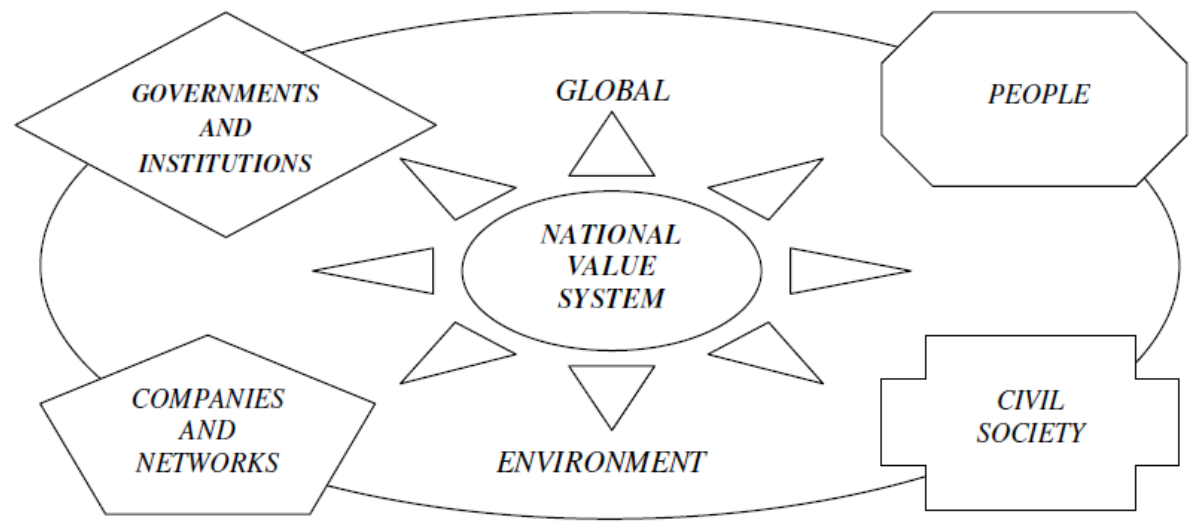




\section{Searching for Virtuous Global Chain Relationships}

\subsection{Fair Trade}

Historically, the fair trade movement started long before the end of world blocs and before people became aware of the complexity of global phenomena.

Consequently, fair trade focused on traditional raw materials, typically agricultural produce which was the main source of wealth in a number of developing countries.

The four pillars underpinning fair trade are, as is well known, the principle of the right price for the producer (frequently fixed by the same), direct contact between producers and consumers, the opportunity to obtain pre-funding for production and for advances in manufacturing, and concern for the natural and social environments (Cotera-Ortiz 2003). The fair trade movement has had worldwide recognition as it upholds an ethical approach to globalization.

In particular, it is interesting to note that the mechanism at work does not eliminate a market; more exactly it tries to customize it. This provides a good example of what building a market entails in relation to what we said previously about markets being a social construct. We are dealing with products on the border between profit and non-profit, between private goods and goods of 'merit'. The development of stable fair relationships over time between producers and traders/vendors is also highly significant.

The emphasis on consumers and their sense of right and wrong increases awareness in developed countries of third world problems, helps local markets to develop and helps people experience real interpersonal relationships, as opposed to de-personalised relationships - these factors are essential to endowing globalization with a human face (Caselli 1994). At the same time, the inherent limitations in this model must not be ignored: the most important shortcoming is marginality with respect to the extent of globalization. This makes it a 'witness' and, as such, it cannot cut much ice on economic phenomena. From this standpoint, the niche configuration for 'idealists' or 'utopians' is evident, fair trade is for people who are prepared to spend a little bit more in order to get a return in moral terms which, however, is not always supported by an appropriate level of quality.

The second shortcoming relates to the fact that the system generates a pricing regime that does not reflect real market conditions. This prevents producers from taking stock of production inefficiencies. In other words, the model does not promote efficient local production. In point of fact, this criticism would be more pertinent if the phenomena were relevant in terms of quantity, although it might be correct with reference to particular products and historical circumstances.

These issues affect the very philosophy of the movement and they continue to be debated vigorously especially in southern countries. In particular, a number of thorny issues are cropping up: the need to become responsible for local development even when this entails reconverting production, promoting relations with mass distribution channels, giving more weight to domestic consumption, the need to foster responsible consumer movements, devising growth processes for quality and certification systems and transparency in managing businesses (CoteraOrtiz 2003). 
However, the current debate is bringing to light the intricacies of the underlying problems and the two main opposing standpoints are struggling to thrash things out: on the one side are those who see fair trade as a means of introducing ethical rules into world trade and, on the other side those who view fair trade as an alternative.

\subsection{Alliances and Business Networks}

Alliances and networks are certainly the most appropriate way in which to spur international relations into creating development mechanisms through established relationships and ensuring they endure. Indeed, the relationship factor is already incorporated into the fair trade circuit. The only difference is that, in this case, it is proposed as the standard for relations between businesses that do not belong and do not intend to belong to any 'ethical' circuit. Such alliances might be made at national and international levels.

There are numerous cases of domestic businesses, including small businesses, which have appeared on the international scene after having set up different types of alliances. Such alliances are to varying degrees of commitment and territorial reach, and are between companies or also involving other entities (e.g. NGOs).

The purpose is not simply trade, but also manufacturing, quality, technology, and so on. A trend that has taken hold in the Third World is that of clusters of businesses as a major tool for building up competitiveness.

The benefits in terms of promoting development are clear: increased bargaining power with foreign buyers, a major factor with regards to sub-contract work with large multinational companies or with foreign buyers. Close cooperation amongst producers can result in increased production capacity, higher quality standards, an increased capacity to channel resources within international cooperation ventures, enhanced training facilities, improved access to credit and an increased capacity to conclude alliances with international institutions and businesses. In point of fact, it is not easy to build up business networks in the Third World on account of economic backwardness, poor human resource development, cultural frictions, the lack of best practices, individualism and the lack of a collaborative culture. It is difficult to bring together companies beset with numerous deficiencies from which no clear leader emerges to act as the common driving force. It is for these reasons that consortiums with one or more leaders fare better as they usually include large companies with either NGOs or schools/universities which perform extension activities.

An interesting example concerns businesses operating in the textiles industry in Peru (Muñoz 2003). The benefits of realizing alliances between large and small businesses have been carefully investigated: technology transfer, support to domestic and international commercialisation capabilities, quality improvements, funding and training.

To date, we have witnessed alliances between entities in developing countries; however, an interesting aspect is provided by alliances between businesses, networks or entities belonging to different countries. A few examples might clarify how this type of alliance could boost development. 
$\square$ A company which manufactures high-quality alpaca pullovers concluded an alliance with an Italian company operating in the Biella area and consequently gained direct access to the Italian and European markets. As a result, output in the manufacturing country rose and trading terms became more favourable to the producer. Subsequently, the existing industrial production process was re-worked in favour of craftsmen. This entailed setting up a network of small workshops that meant a lot of effort in order to increase quality and ensure regular supplies. The outcome was positive and the prices paid to the local craftsmen have grown considerably. This example shows how a partnership also values local traditions and craftsmanship.

$\square$ A second example is provided by the multinational company Nestlé. When faced with a slump in coffee prices, and having established that it was unlikely for a short-term trend reversal to occur, the company decided to establish an alliance with producers in order to shortcut commercialisation channels (in the footsteps of fair trade). More importantly, it was designed to boost added value in the countries of origin by implementing production transformation processes that entailed improving quality and development of the domestic market. In the same vein, ILLY has created coffee universities in Latin America.

Other examples are provided by the numerous success stories of small joint ventures. Small businesses have successfully managed to set up enterprises with local partners which, as well as being vehicles for transmitting technology and knowledge, also succeed in diffusing different business models and cultures with the ensuing positive results.

Alliances are all the more significant when the partners are public institutions or NGOs and businesses. The resulting internationalisation processes can benefit in terms of development effectiveness by relying, in part, on the potential to attract resources from international cooperation. In addition to the funding of large projects, a focus of interest is provided by extensive micro-credit schemes that are fairly widespread throughout the Third World - even if results are not always encouraging.

\subsection{The Corporate Social Responsibility Alternative}

Corporate social responsibility (CSR) is another question closely linked to the issues we have been dealing with. One of the most widely accepted definitions is that provided by the European Commission Green Paper (2001): 'companies voluntarily integrate social and environmental concerns into their commercial transactions and relations with interested parties'. In the broadest sense, the concept of CSR is linked to that of sustainable development which is: 'development which satisfies the needs of the present world without compromising the capacities of future generations to satisfy their needs when their time comes' (World Commission on Environment and Development, 1987). Both definitions emphasize the voluntary aspect of CSR. As stated previously, the breadth of activity is invariably wider than statutory provisions and involves the will to respond to economic, social and environmental expectations. 
The various stakeholders express these expectations and companies take them into account, both internally and externally, as they are aware of the importance such conduct has in firm duration.

It is now self-evident that responsible social behaviour cannot but tend to generate international relations which incorporate an ethical dimension.

Obviously, not all companies involved in the building of networks and alliances set out with this type of awareness, but it is equally obvious that a CSR stance cannot but be oriented to the production of social value even at an international level.

It must not be forgotten that the force which propels CSR growth has come, in no small measure, from the macro-environment and in particular from expansion in globalization processes. The business activity areas in which this is evident are as follows:

- human resource management: this covers numerous issues including multicultural issues, the protection of workers' rights and employment conditions, the concern about workers from the Third World, attention to the development of human capital in the countries of operation, and so on. This is a typical CSR topic in international relations. There have been numerous cases of unethical behaviour (for instance the exploitation of juvenile workers, see the Nike case), heavily penalised by the market and generating a significant change in attitude;

- extension of formal official CSR tools to the international level including, for instance, charters upholding values and ethical codes in order to spread understanding and use to all countries where the businesses operate;

- the drafting of official documents, such as social corporate financial statements, which help generate awareness both internally and externally of the company's commitment to the creation of a social and environmental network of value;

- coordination of socially responsible marketing activities and the adoption of worldwide cause-related marketing;

- ethical control of the supply chain. From a globalization standpoint, this is certainly the most significant issue as it concerns the ability to establish responsible relations with producers in any part of the world. Clearly, moving beyond the traditional scope of fair trade, this entails developing forms of trade in goods and services as well as direct investments and new forms of internationalisation, which attribute value, respect and promote producers' skills to develop and become active players in the internationalisation processes that concern them;

- ethical correctness in international financial transactions (and the promotion of alternative forms of funding);

- ongoing relations with local communities in the countries of origin for raw materials and products as well as in distribution countries;

- protection of the environment on a world scale. 


\section{Alliances for the Development of Human Capital}

The human capital issue is now fully recognized as being crucial to all countries. Some experts estimate that human capital represents $80 \%$ of wealth and that two thirds of economic activity depends on employee skills (Casadei 2003).

Accordingly, human capital growth is decisive for the development of production and, consequently, of competitiveness.

Recent in-depth studies have shown that the amount of individual human capital is the variable which best explains inequalities in terms of wage income.

Therefore, 'the means to reduce the gap between developing and industrialized countries entails a massive investment in human capital and boosting the social and economic infrastructure of the poorest countries' (Casadei 2003).

From this point of view, the actions required in order to increase the level of investment in human capital fall into four areas: education (school and university), professional training inside and outside companies, information and health services. Above all, it must be emphasized that we are not endorsing 'any old' form of investment; it is not merely a question of spending money for training. Instead it means thinking up training projects for human capital which really place people at the forefront. Indeed, training is not the same thing as education and only when the training process triggers off educational processes will it be possible to influence the employment culture - thereby deploying all the related development potential effectively.

Obviously, these issues cannot be separated from ethical considerations on globalization, even if the same do not merely concern business. International alliances that undoubtedly promote the growth of human capital imply relations between entire value production systems and not only between businesses. They involve governments at the national and local levels, educational institutions, research centres, non-profit organizations and so on.

There is no dearth of examples: the aforementioned coffee university founded by ILLY, inter-university cooperation, various international cooperation projects (including those entailing debt cancellation in developing countries) and regional initiatives (like the training school for Brazilian health managers sponsored by the northern Italian region of Lombardy).

In conclusion, the ethics or justice of international relations must not be limited to airing principles on the nature of international trade. It must engage all the multifarious manifestations of the globalization process, therein identifying innovative means to handle relations in addition to devising an overall development strategy for Third World countries (including all the aspects related to reforms, production innovations, technology transfer and the re-conversion of sectors). It is a mistake to think of wealth as something that is given, over which claims may be made in terms of distribution. The crux of the problem lies in the ability to generate more wealth not only in terms of quantity but also in terms of quality. Only in this way will the divide between production, globalization and development be closed. 
Fair relations on a worldwide basis will generate connections between different value production systems, and draw them into a global network where material and intangible/cultural elements merge in order to produce a flow of international relations. The content of these relations will not be merely economic but will favor people and cultures meeting. When all is said and done, something more that the mere expediency of economic relations must be put into play to foster relations, including culture, values and convictions regarding the meaning of life and the aims of economic action.

\section{Bibliography}

AA.VV., Monografia. Costruire il mercato, Persone \& Imprese, n. 2, 1995.

Amin S., Come funziona il capitalismo? Lo scambio ineguale e la legge del valore, Jaca Book, Milan, 1974.

Baran P.A., Sweezy P.M., Il capitale monopolistico, Einaudi, Turin, 1978.

Beretta S., Maggioni M., Senn L., 'Settimo: non rubare' nel commercio internazionale, Communio, n. 2, 1998 .

Casadei R., Difendiamo il futuro: investiamo in capitale umano, Tempi, Milan 2003.

Caselli C. (ed.), Primi fra gli ultimi, ultimi fra i primi, Liguori, Naples, 1994.

Caselli C., Empresas y empresarios: camino al éxito y producción del valor económico y social, Studium, n. 3, 2002.

Caselli C., L'avventura dell'internazionalizzazione. Logiche e strumenti per le imprese, Giappichelli, Turin, 1994.

Caselli C., La hilera del valor económico y social, Working Paper, Universidad Católica Sedes Sapientiae, Lima, 2003.

Caselli C., Las culturas económicas en el mundo contemporáneo: un desafío para la universidad, Studium, n. 2, 2002.

Caselli L. (ed.), Le parole dell'impresa. Guida alla lettura del cambiamento, F. Angeli, Documenti Isvet, Milan, 1995.

Cotera A., Ortiz H. (ed.), Comercio justo en América Latina, Atti del Convegno, Lima, 2003.

Dunning J.H., Le imprese internazionali in un mondo in mutamento, Moneta e Credito, dicembre 1982.

Dunning J.H., Wymbs C., The Challenge of Electronic Market for International Business Theory, International Journal of the Economics of Business, vol. 8, n. 2, 2001.

http://dx.doi.org/10.1080/13571510110051432

Eliot T.S., Choruses from 'The rock', Faber \& Faber, London, 1963.

Gunder Frank A., Capitalismo e sviluppo in America Latina, Einaudi, Turin, 1974.

Molteni M., Responsabilità sociale e performance d'impresa. Per una sintesi socio competitiva, Working Paper, 2003.

Muñoz W., Los conglomerados textiles en el Cono Norte de Lima, Universidad Católica Sedes Sapientiae, Lima, 2003.

Onida F., Economia degli scambi internazionali, Il Mulino, Bologna, 1984.

Palloix C., I problemi dello sviluppo nell'economia aperta, Jaca Book, Milan, 1970.

Sapelli G., Etica, in Caselli L. (ed.), Le parole dell'impresa. Guida alla lettura del cambiamento, F.Angeli, Documenti Isvet, Milan 1995.

Scola A., Teologia, etica e affari, Studi perugini, n. 9, gennaio-giugno 2000.

UNCTAD, Informe sobre el comercio y el desarrollo, New York and Ginevra, 2003.

UNCTAD, World Investment Report, New York and Ginevra, 2002. 
(c) SYMPHONYA Emerging Issues in Management, n. 1, 2003

symphonya.unimib.it

Vittadini G., Sussidiarietà. La riforma possibile, Etas Libri, Milan, 1998.

World Bank, Globalization, Growth and Poverty, New York, 2000. 